\title{
Dengue Hepatitis: A Case Report
}

\author{
Jagadish Kumar Kalenahalli ${ }^{1, *}$; Shashirekha Priyadarshini ${ }^{1}$; Vadambal Gopalakrishna \\ Manjunath ${ }^{1}$; Umesh Lingappa ${ }^{1}$ \\ ${ }^{1}$ Department of Pediatrics, JSS Medial College, JSS Univeristy, Mysore, India \\ ${ }^{*}$ Corresponding author: Jagadish Kumar Kalenahalli, Department of Pediatrics, JSS Medial College, JSS Univeristy, Mysore, India. Tel: +91-9844281859, Fax: +91-08212335556, \\ E-mail: jagdishmandya@gmail.com
}

Received: February 2, 2015; Accepted: March 8, 2015

\begin{abstract}
Introduction: Dengue fever is the world's most important hemorrhagic fever, especially in America, Pacific islands, and Asia. In countries like ours where viral hepatitis, malaria, enteric fever are common; it represents a challenge to identify the etiology of acute fever complicated by hepatitis.

Case Presentation: We report a case of acute hepatitis in a 7-year-old male with dengue hemorrhagic fever. The child responded to IV fluids and symptomatic treatment.

Conclusions: Dengue fever should be considered, when liver functions are deranged, because they are potential candidates for acute fulminant hepatic failure apart from routine hepatotropic viruses. We would like to emphasize the importance of considering dengue infection in the differential diagnosis of acute hepatitis in children in developing countries like India.
\end{abstract}

Keywords: Dengue; Hepatitis; Jaundice

\section{Introduction}

Dengue fever is an acute infection caused by an arbovirus of Flavivirus genus, which is transmitted by Aedes aegypti. Dengue infection is endemic in the tropical and subtropical countries with more than 100 million reported cases and 24000 deaths annually (1). Atypical clinical manifestations have become common in the last few years (2). Mild hepatic dysfunction in dengue fever is usual; however, acute hepatitis presenting as jaundice is not common. We describe a case of acute hepatitis in a 7-yearold male with dengue hemorrhagic fever. Dengue hepatitis needs to be taken into consideration in the differential diagnosis of patients with acute febrile jaundice.

\section{Case Presentation}

A 7-year-old male child was referred to our hospital with fever and myalgia since ten days and vomiting and jaundice since seven days before admission. There was no history of bleeding, exposure to hepatotoxic drugs, and any significant past medical or surgical illness. On clinical examination, child was found irritable, febrile $\left(101^{\circ} \mathrm{F}\right)$, icteric with facial flushing and macular rashes over the body. His pulse rate was $112 / \mathrm{min}$, respiratory rate was $24 / \mathrm{min}$, and blood pressure was 74/50 mmHg. Abdominal examination revealed $4 \mathrm{~cm}$ tender hepatomegaly and free fluid. Chest examination revealed diminished breath sounds in the right infrascapular and right infra-axillary areas. In view of fever with jaundice, diagnosis of acute hepa- titis was made and blood was sent for viral markers and other relevant investigations. Complete blood count results were as follows: $\mathrm{Hb}, 13.3 \mathrm{~g} / \mathrm{dL}$; hematocrit, $40 \%$; total leukocyte count, $10300 / \mu \mathrm{L}$; and platelet count, $68000 / \mu \mathrm{L}$. Liver function tests showed conjugated hyperbilirubinemia (total bilirubin: $4.6 \mathrm{mg} / \mathrm{dL}$ direct bilirubin: $3.12 \mathrm{mg} /$ dL); AST, 287 U/L; ALT, 199 U/L; and ALP, 399 U/L. His renal function tests and blood sugar were normal. Values of Prothrombin Time and activated Partial Thromboplastin Time were within normal ranges. The ultrasound exam of his abdomen showed hepatomegaly with gall bladder wall thickening, minimal ascites, and bilateral pleural effusion. His blood culture was sterile. The Widal test, peripheral blood smear for malaria parasite, and leptospira serology were negative. Tests of IgM antiHAV, HBsAg, antiHCV, and antiHEV were also negative. Both IgM and IgG antibodies against dengue were strongly positive making a diagnosis of dengue infection.

Child was managed conservatively with continuous IV fluids and daily vital monitoring. On the second day, his platelet count became $59000 / \mu \mathrm{L}$, on third day it increased to $68000 / \mu \mathrm{L}$, and on the fifth day it reched 1.3 lakhs/ $\mu \mathrm{L}$. Child became afebrile on day 4 with blood pressure being normal without IV fluids. Jaundice slowly disappeared by day 7 and child was discharged on the eighth day. His LFT and ultrasound abdomen were normal at the time of discharge.

Copyright (C) 2015, Infectious Diseases and Tropical Medicine Research Center. This is an open-access article distributed under the terms of the Creative Commons Attribution-NonCommercial 4.0 International License (http://creativecommons.org/licenses/by-nc/4.0/) which permits copy and redistribute the material just in noncommercial usages, provided the original work is properly cited. 


\section{Discussion}

Hepatic dysfunction is common in dengue virus infection and is attributed to direct virus infection of hepatocytes or the consequence of host immune response against virus (3). Liver injury has been described in the literature since 1967 (4). Out of 392 infective causes of hepatitis patients, $8.4 \%$ of cases were due to dengue infection according to a study by Syhavong et al. (5). The spectrum of hepatic involvement in dengue infection varies from mild injury with elevated aminotransferases to severe injury with jaundice. Hepatic failure and severe hepatic disturbances occur more commonly in dengue shock syndrome and hemorrhagic fever $(2,5,6)$. Hepatomegaly is one of the common clinical features in dengue infection, which manifests in $79-100 \%$ of patients with dengue infection (5-7). The elevation of aminotransferases has been associated with disease severity and is a good predictor of development of dengue hemorrhagic fever (8). Among 1585 serologically confirmed cases from Brazil, $65.2 \%$ of patients had elevation of aminotransferases and enzymes were more elevated in Dengue Haemorrhagic Fever; however, none of them had fulminant hepatitis (2). One characteristic of liver involvement during dengue is the greater elevation of AST in comparison to ALT (2). Release of AST from damaged myocytes may be the reason for their difference in rise $(2,7)$. Kuo et al. noted that AST begins to increase from the third day of illness, up to an average of 9.25 fold on the sixth day. After a peak on the seventh to eighth day, AST declines and typically normalizes by 3 weeks (7). In a study by Kumar et al. (4), dengue infection was responsible for $18.5 \%$ of acute hepatic failure of children in India. However, Poovorawan et al. reported that $34.3 \%$ of their cases pediatric dengue infections were the major cause of acute hepatic failure in Thai children (9). Jaundice in dengue fever has been associated with fulminant hepatic failure and by itself is a poor prognostic factor (10).

The predictors of liver damage in dengue infection have been identified as thrombocytopenia, increased hematocrit, female sex, elevated enzymes, and DHF (2). Thomas et al. (11) observed that patients with diarrhea and those who were taking paracetamol (more than $60 \mathrm{mg} / \mathrm{kg} / \mathrm{day}$ ) before admission were associated with the development of acute hepatitis in dengue fever. They also reported mortality of 7.1\% in patients who developed hepatitis. In a study in Pakistan, patients with dengue infection having an SGPT > $300 \mathrm{mg} / \mathrm{dL}$, bleeding, altered mental status, and shock at the time of presentation were all significantly associated with mortality (2.7\%). They noted jaundice in $3 \%$, severe hepatitis in $15 \%$, and mild to moderate hepatitis in $71 \%$, however, $14 \%$ of them had normal ALT. Hence measurement of AST and ALT are mandatory to see the liver involvement (12). Wong et al. observed elevation of transaminase of 10-fold greater than the normal upper limit for AST and ALT in $10.2 \%$ and 9.5\% of their patients, respectively. they identified the predictive factors for liver damage as follows: dengue hemorrhagic fever, secondary infection, thrombocytopenia, high blood concentration, female sex, and children (13). Clinical jaundice was noted in less than $2 \%$ of 644 patients with dengue, of whom 8 had severe bleeding. In terms of correlation between transaminase levels and markers of disease severity, during the critical period, AST and ALT levels were significantly higher in the dengue patients experienced shock compared to those without shock (reported in a study from Vietnam). They also observed jaundice and acute liver failure developing relatively late in the disease course, usually without evidence of vascular leakage severe enough to cause shock (14). Therefore severe hepatitis can be considered as a poor prognostic indicator in dengue infection.

Our case presented with fever and jaundice for 7 days; the probable differential diagnosis comprised viral hepatitis, malaria, leptospirosis, and enteric fever. On examination, the patient had macular rash, jaundice, pleural effusion, and ascites. All the investigations for the abovementioned differential diagnosis were negative in the patient. The persistence of fever after the appearance of jaundice with thrombocytopenia along with the evidence of plasma leakage favored the diagnosis of dengue (15). Dengue may cause hepatic injury similar to that of conventional viral hepatitis (6). Dengue fever also causes elevation of aminotransferases similar to that in patients with viral hepatitis. The elevation in the AST level is usually greater than that of ALT in dengue infection, which is uncommon in patients with viral hepatitis A, B, or C (2). Our patient also had greater elevation of AST compared to ALT elevation. Dengue fever should be considered when liver functions are deranged, because they are potential candidates for acute fulminant hepatic failure apart from routine hepatotropic viruses. We would like to emphasize the importance of considering dengue infection in the differential diagnosis of acute hepatitis in children in developing countries like ours.

\section{Authors' Contributions}

Jagadish Kumar Kalenahalli and Shashirekha Priyadarshini collected the data and drafted the manuscript. Vadambal Gopalakrishna Manjunath and Umesh Lingappa analyzed the data and helped in manuscript writing. The final manuscript was approved by all authors. All were involved in patient care. Jagadish Kumar Kalenahalli acted as guarantor.

\section{References}

1. Gibbons RV. Dengue: an escalating problem. Bri Med J. 2002;324(7353):1563-6.

2. Souza LJ, Alves JG, Nogueira RM, Gicovate Neto C, Bastos DA Siqueira EW, et al. Aminotransferase changes and acute hepatitis in patients with dengue fever: analysis of 1,585 cases. Braz J Infect Dis. 2004;8(2):156-63.

3. Seneviratne SL, Malavige GN, de Silva HJ. Pathogenesis of liver involvement during dengue viral infections. Trans $R$ Soc Trop Med Hyg. 2006;100(7):608-14.

4. Kumar R, Tripathi P, Tripathi S, Kanodia A, Venkatesh V. Preva- 


\section{Kalenahalli JKet al.}

lence of dengue infection in north Indian children with acute hepatic failure. Ann Hepatol. 2008;7(1):59-62.

5. Syhavong B, Rasachack B, Smythe L, Rolain JM, Roque-Afonso AM Jenjaroen $\mathrm{K}$, et al. The infective causes of hepatitis and jaundice amongst hospitalised patients in Vientiane, Laos. Trans R Soc Trop Med Hyg. 2010;104(7):475-83.

6. Mohan B, Patwari AK, Anand VK. Hepatic dysfunction in childhood dengue infection. J Trop Pediatr. 2000;46(1):40-3.

7. Kuo CH, Tai DI, Chang-Chien CS, Lan CK, Chiou SS, Liaw YF. Liver biochemical tests and dengue fever. Am J Trop Med Hyg. 1992; 47(3):265-70.

8. Petdachai W. Hepatic Dysfunction in Children with Dengue Shock Syndrome. Dengue Bull .2005;29:112-8.

9. Poovorawan Y, Hutagalung Y, Chongsrisawat V, Boudville I, Bock HL. Dengue virus infection: a major cause of acute hepatic failure in Thai children. Ann Trop Paediatr. 2006;26(1):17-23.
10. Nguyen TL, Nguyen TH, Tieu NT. The impact of dengue haemorrhagic fever on liver function. Res Virol.1997;148(4):273-7.

11. Thomas L, Brouste Y, Najioullah F, Hochedez P, Hatchuel Y, Moravie $\mathrm{V}$, et al. Predictors of severe manifestations in a cohort of adult dengue patients. J Clin Virol. 2010;48(2):96-9.

12. Almas A, Parkash O, Akhter J. Clinical factors associated with mortality in dengue infection at a tertiary care center. Southeast Asian J Trop Med Public Health. 2010;41(2):333-40.

13. Wong M, Shen E. The utility of liver function tests in dengue. Ann Acad Med Singapore. 2008;37(1):82-3.

14. Trung DT, Thao le TT, Hien TT, Hung NT, Vinh NN, Hien PT, et al. Liver involvement associated with dengue infection in adults in Vietnam. Am J Trop Med Hyg. 2010;83(4):774-80.

15. Itha S, Kashyap R, Krishnani N, Saraswat VA, Choudhuri G, Aggarwal R. Profile of liver involvement in dengue virus infection. Natl Med J India. 2005;18(3):127-30. 